Please quote as: Paschou, Theoni; Rapaccini, Mario; Peters, Christoph; Adrodegari, Federico \& Saccani, Nicola: Developing a maturity model for digital servitization in manufacturing firms. 2020. - International Joint Conference on Industrial Engineering and Operations Management (IJCIEOM). - Novi Sad, Serbia. 


\title{
ICIEOM
}

International Joint Conference on Industrial Engineering and Operations Management- ABEPRO-ADINGOR-IISEAIM-ASEM (IJCIEOM 2019). Novi Sad, Serbia, July $15-17^{\text {th }}$

\section{Developing a Maturity Model for Digital Servitization in Manufacturing Firms}

\author{
Paschou T1', Rapaccini $\mathbf{M}^{2}$, Peters $C^{3}$, Adrodegari F ${ }^{1}$, Saccani $\mathbf{N}^{1}$
}

\begin{abstract}
In today's rapidly changing markets, manufacturing firms are increasingly challenged by the convergence of digital technologies and servitization, which is defined as Digital Servitization. Enterprises struggle to grasp this phenomenon's vision, constantly facing pressures to obtain and retain competitive advantage, inventing and reinventing new products and services, reducing costs and time to market, and enhancing quality at the same time. They need to define improvement actions to be taken to navigate through the transformation process and prioritize between different activities. Prior research has highlighted the importance of how to proceed into this transformation, however less emphasis has been put on suggesting suitable activities that fit the organization's current status and future goals. To overcome this challenge, we propose a maturity model for digital servitization that serves as an assessment tool. The design of our maturity model is grounded in literature and expert interviews. During its evolutionary development, we gathered, structured and organized several critical requirements for digital servitization. We could also explore and highlight important attributes that must be examined by companies during the transformational process. We contribute by our proposed maturity model that serves companies not only as a diagnostics tool to assess the current situation, but also as a guideline for continuous improvement.
\end{abstract}

Keywords: Digital servitization, maturity model, digital transformation, manufacturing, assessment

\section{Introduction}

In today's world, the growing digital disruption across industries is blurring boundaries and forcing industrial enterprises to improve their agility and responsiveness to gain ability to manage the whole value-chain. Recent research suggests that the application of digital technologies (DTs) can further advance servitization by enabling sophisticated and novel service offerings (Grubic, 2018; Lerch and Gotsch, 2015). In fact, the adoption of digital technologies such as the Internet of Things (IoT), Data and Analytics, Artificial Intelligence can alter the features of the delivered services significantly (Ardolino et al., 2018; Holler et al., 2017; Rymaszewska et al., 2017) and enable novel business models (Adrodegari et al., 2017), thus, reshaping industry competition (Porter and Heppelmann, 2014). Indeed, DTs shape servitization strategies, structures and activities aiming at increasing the service delivery efficiency and value of service offerings (Lerch and Gotsch, 2015). For instance, KONE, one of the largest global elevator companies, developed, sophisticated condition monitoring and predictive maintenance services together with IBM. Both these services are based on IoT technology and have resulted in lower downtime and speed up equipment restoration (Ardolino et al., 2018).

The convergence of DTs and servitization is called digital servitization and refers to the development of new services and/or the improvement of existing ones through the use of DTs by enabling new digital business models, finding ways of co-creating value, generating knowledge from data, improving a firm's operational performance and gaining competitive advantage over rivals (Sklyar et al., 2019a; VendrellHerrero et al., 2017) and received lots of attention over the last years from the research community and practitioners. Despite the phenomenon's growing relevance, the issue of defining how digital servitization changes a company's strategy, processes, and culture remains unexplored (Belvedere et al., 2013).

${ }^{1}$ Paschou Theoni ( $₫$ e-mail: t.paschou@unibs.it)

Deptartment of Mechanical and Industrial Engineering. University of Brescia. Via Branze 38, 25123, Brescia, Italy 


\section{IJCIEOM}

International Joint Conference on Industrial Engineering and Operations Management- ABEPRO-ADINGOR-IISEAIM-ASEM (IJCIEOM 2019). Novi Sad, Serbia, July $15-17^{\text {th }}$

Evidence shows that organizations often struggle with understanding the impact of digital servitization on their business and industry (Sklyar et al., 2019b). One key barrier is their inability to decide where to begin their own transformation process. To date, to the best of our knowledge, the existing research has not provided tools, such as maturity models for practitioners to master this transformation. Specifically, more attention has to be focused on helping organizations to decide when and why they need to take an action to progress and teaching them which actions should be considered. The introduction of such maturity model in the digital servitization, could therefore allow managers to position and compare their current state to the best-practices in related business fields and map their new strategy accordingly, which will increase the firm's overall performance.

Hence, the aim of our research project is to develop a maturity model (MM) that can ease the decision making, and assess the digital servitization maturity in manufacturing companies based on highly relevant requirements. To achieve our goal, we follow the maturity development process of (Becker et al., 2009a) and aim to answer the following two research questions.

$R Q 1$ : What are the key requirements for digital servitization in manufacturing?

$R Q 2$ : What stages can be observed in the process of digital servitization?

In pursuit of answering the two research questions, our paper is structured as follows. Section 2 sets the theoretical background. Section 3 describes the research method, and Section 4 presents the maturity model for digital servitization. Section 5 concludes and suggests avenues for further research.

\section{Theoretical Background}

Although, the phenomenon of digital servitization has been of a great interest for researchers of various disciplines the last years (Paschou et al., 2018), there is a lack of a more interpretative research with the goal of supporting decision-making. Descriptive models (maturity models) for practitioners need to be developed to position companies towards the journey of digital servitization by defining how the adoption of digital technologies changes the whole organization in practice (Belvedere et al., 2013; Ostrom et al., 2015). In particular, to define a digital servitization strategy, managers need to understand the current state of their organization. This transformation is not a linear process, but there are different possible courses of actions. It would be beneficial for managers to know about these difficulties, in order to make an informed decision about prioritizing between different steps and to lay the foundation for successful change. Therefore, we need to know more about how companies actually face such a transformation, what makes them successful, and how organizations approach their transformation. A maturity model provides some guidance in this respect, since it gives an overview of the different areas and maps out typical paths of how organizations go about their digital servitization.

According to (Becker et al., 2009b), maturity models consist of a sequence of maturity levels for a class of objects and represent an anticipated, desired, or typical evolution path of these objects shaped as discrete stages. Their application enables firms to achieve competitive advantages (Wendler, 2012), by generating awareness of the analyzed aspects (their state, importance, potentials, requirements, complexity), and by serving as reference frame to implement a systematic and well-directed approach for improvement, ensuring a certain quality, avoiding errors, and assessing one's own capabilities on a comparable basis. There are several MMs but in this study, we use the Capability Maturity Model, which defines a set of process areas that reflect organizational capabilities which have to be developed to achieve the maturity goal of the service development process.(Paulk and Curtis, 1993), as the main reference due to its wide acceptance in industry.

The development of a MM entails critical requirements that occur throughout the digital servitization process and should be rooted in both scientific grounding and practical relevance. In the case of digital servitization, these critical requirements also impact the manner that a company relates to the other chain elements such as customers, partners, competitors (Baines and Lightfoot, 2014) and internal relationship changes. Hence, this study has identified four main dimensions (strategy, customer experience, business processes, organization and culture) to analyze how they should be considered during the digital servitization process of manufacturers. The four dimensions were defined by using the St.Gallen Business Engineering Map (Leimeister et al., 2014) as a guide to group the critical requirements within the same 


\section{IJCIEOM}

International Joint Conference on Industrial Engineering and Operations Management- ABEPRO-ADINGOR-IISEAIM-ASEM (IJCIEOM 2019). Novi Sad, Serbia, July 15-17 $7^{\text {th }}$

type of relationship. The critical requirements for all the dimensions are obtained from the literature and are used to create an initial concept of the maturity model.

\section{Research Methodology}

In this study, to reduce complexity, we decided to apply the development process of (Becker et al., $2009 \mathrm{~b}$ ), one of the most popular models, to develop our MM.

Table 1 Procedure model

\begin{tabular}{cllll}
\hline & Problem identification & Comparison of existing MMs & $\begin{array}{c}\text { Model } \\
\text { development }\end{array}$ & $\begin{array}{c}\text { Model } \\
\text { evaluation }\end{array}$ \\
\hline $\begin{array}{c}\text { Performed } \\
\text { activities }\end{array}$ & $\begin{array}{l}\text { Problem identification and } \\
\text { motivation }\end{array}$ & $\begin{array}{l}\text { 1. Deduction of maturity model } \\
\text { requirements } \\
\text { 2. Identification and evaluation } \\
\text { of existing maturity models }\end{array}$ & $\begin{array}{l}\text { Conceptualization } \\
\text { of maturity levels }\end{array}$ & Evaluation \\
$\begin{array}{c}\text { Used } \\
\text { techniques }\end{array}$ & $\begin{array}{l}\text { 1. Initial literature review } \\
\text { 2. Exploratory expert }\end{array}$ & In-depth literature review & $\begin{array}{l}\text { Model } \\
\text { development \& } \\
\text { expert interviews }\end{array}$ & $\begin{array}{l}\text { Expert } \\
\text { interviews }\end{array}$ \\
\hline
\end{tabular}

In the first step (Problem identification), we specified the research problem and focus of the MM, provided practical relevance and justified the artefact's value based on an initial literature review and exploratory interviews with two experts to get better insights. Based on the problem identification, in the second step (Comparison of existing $M M s$ ), we gather requirements by conducting a systematic literature search using the Scopus database, which is widely acknowledged as a world leading source and provides the best coverage in this research field (Burnham, 2006). We applied the search combination of servitization ("servitization", "product (-) service system* (PSS/IPSS)", "integrated solution*”, "service transformation", service infusion") and different terms for digital transformation and technologies ("digital technology/ies", "digitization", "Artificial Intelligence", "Big Data", "Cloud", "Digital Technologies", "digitalization", "Industry 4.0," Internet of Things", etc.). The search, between 2000 and 2019, yielded 86 usable articles. These articles were used to derive an initial list of requirements, which was structured according to the four MM dimensions derived in the theoretical background section. For the coding process the software Atlas.ti was used. Moreover, we operated a second literature review (using keywords such as "digital servitization", "servitization", "business/enterprise/organizational transformation", "digital transformation", "assessment model", "maturity model") to identify any shortcomings or lack of transferability of existing MMs, which are devoted to same or similar domains. In particular, 16 studies emerge from the field of servitization, (Alvarez et al., 2015; Neff et al., 2014) and 11 from digital transformation. Subsequently, we analyzed the MMs according to their domains and functionalities as well as their capability to address the defined research problems. In the third step (Model development), we used model adoption mechanisms (Becker et al., 2007) in the rigorous creation of a MM (structure and content). After formulating the model, the study sought expert opinions to confirm support for the model. Emails with a questionnaire to guide open conversations were sent to ten individuals, academics and practitioners involved with digital servitization for over a decade. There were six respondents who provided in-depth feedback through interviews regarding the model, which had a duration of 60-120 minutes each one. The majority of the responses acknowledged the importance of evaluating manufacturers' use of digital servitization and supported the overall structure of the model. Comments included suggestions for definition of stages, notes about wording, suggesting the possibility of needing less stages, need for clarifying requirement description, questions about how the model will be measured and by whom, and proposing extra dimensions/requirements. These opinions were taken into consideration and the model was revised accordingly in order to be more precise and complete. During the last step (Model evaluation,), we evaluated the comprehensiveness of the model, validity in selfassessment and the capability of supporting the future development of a roadmap with the same experts, 


\section{IJCIEOM}

International Joint Conference on Industrial Engineering and Operations Management- ABEPRO-ADINGOR-IISEAIM-ASEM (IJCIEOM 2019). Novi Sad, Serbia, July 15-17 $7^{\text {th }}$

discussing the final version of the MM. Table 1 describes the steps according to the tasks performed and the techniques used achieved in complementing our research.

\section{Proposed Digital Servitization Maturity Model}

The identified requirements both from literature and expert interviews were summarized in four dimensions. For each dimension, corresponding maturity criteria were defined, which describe the fields of action. Activities in these fields show the penetration of digital servitization maturity. Hence, we employed "Strategy", "Customer Experience", "Business Processes" and "Organization and Culture" as dimensions that serve not only as a conceptual basis but for collecting the exploratory identified requirements but also as a theoretical lens for the MM (see Table 2).

Table 2 Identified dimensions and maturity criteria in the individual steps of the study

\begin{tabular}{|c|c|c|c|}
\hline Dimensions & Requirements & Literature & Expert interviews \\
\hline \multirow{4}{*}{ Strategy } & Strategic orientation & $\checkmark$ & $\sqrt{ }$ \\
\hline & Business model & $\checkmark$ & $(\sqrt{ })$ \\
\hline & Digital service offering & $\sqrt{ }$ & $(\sqrt{ })$ \\
\hline & Digital service ecosystem & $(\sqrt{ })$ & $\checkmark$ \\
\hline Customer & Customer centricity & $\checkmark$ & $\checkmark$ \\
\hline \multirow[t]{2}{*}{ Experience } & Customer trust & $(\sqrt{ })$ & $\sqrt{ }$ \\
\hline & Production & $\checkmark$ & $\checkmark$ \\
\hline \multirow[t]{3}{*}{ Business Processes } & Marketing & $(\sqrt{ })$ & $(\sqrt{ })$ \\
\hline & Human resources & $(\sqrt{ })$ & $\checkmark$ \\
\hline & Digital service business mindset and culture & $(\sqrt{ })$ & $\sqrt{ }$ \\
\hline Organization and & Governance and leadership & $(\sqrt{ })$ & $\checkmark$ \\
\hline \multirow[t]{3}{*}{ Culture } & Organization design and talent management & $\sqrt{ }$ & $(\sqrt{ })$ \\
\hline & Competences & $\checkmark$ & $\checkmark$ \\
\hline & $\boldsymbol{V}=$ frequent mention & ntion & \\
\hline
\end{tabular}

The Strategy of digital servitization is embedded within the overall business strategy and focuses on how the business transforms or operates to increase its competitive advantage through digital initiatives in service. "Strategic Orientation" was identified as an important prerequisite for digital servitization and it refers to the exploitation of the overall growth strategy aiming at developing digital service offerings and innovating the company's portfolio by keeping its heritage (Allmendinger and Lombreglia, 2005; Bustinza et al., 2015). "Business Model", another critical requirement, refers to the different technologyenabled business models that facilitate firms to achieve a competitive advantage by providing customer knowledge-based digital service offerings during the entire product life cycle (Frank et al., 2019; Kohtamäki et al., 2019). In addition, "Digital Service Offering" applies to the enrichment of the existing but also the creation of totally new service offerings enriched by digital technologies that bring digital and physical systems together creating customer value and revenue streams (Baines and Lightfoot, 2014). The last requirement of this dimension is the "Digital Service Ecosystem" and makes reference to the relationship between the company and business partners (R\&D organizations, technology incubators, startups), enabled by platforms, which aims at gaining access to resources such as technology intellectual property, or people to increase the organization's ability to improve, innovate and grow, balancing security and privacy needs with the ability to flex capacity according to business demand (Cenamor et al., 2017; Sklyar et al., 2019a). Customer Experience focuses on the necessity of considering customers' needs and interests as the basis for developing digital service offerings. The first requirement, that we identified is the "Customer Centricity" and deals with a set of procedures and practices for assessing closer customers' preferences and continuously evolving needs on digital service offerings, to enhance the competitive position and strengthen customer relationships (Coreynen et al., 2017). Experts stressed the "Customer Trust", which refers to how the customer's trust is build and how the perceived risks (functional, psychological/safety, privacy) are evaluated by them (Paluch and Wunderlich, 2016). The dimension of Business Processes contains the way of executing and evolving a company's operations by 


\section{IJCIEOM}

International Joint Conference on Industrial Engineering and Operations Management- ABEPRO-ADINGOR-IISEAIM-ASEM (IJCIEOM 2019). Novi Sad, Serbia, July 15-17

using digital technologies aiming at driving strategic management and enhancing service business efficiency and effectiveness. The first requirement is "Production" and indicates the way processes are executed, monitored and managed. It consists of internal processes (the way inputs are transformed to outputs, products and services are integrated through digital technologies to create value for the customers and end users), supply chain orchestration (the way the firm employs digital technologies to manage the value network of all actors and individuals that interact to deploy resources and applied competences in order to create value) and digital innovation (practices based on digital technologies that support research, design, and development of new product-service offerings) (Belvedere et al., 2013; Vendrell-Herrero et al., 2017). "Marketing" requirement include the pricing, the process whereby a business sets the price at which it will sell its digital service offerings and value co-creation, which occurs through interactions among providers and customers by integrating resources and applying competences (Bonfanti et al., 2018; Valencia et al., 2015). "Human Resources" requirement depicts to services provided by an HR department to business operations. HR operations include administrative services, recruitment, job analysis, and employee relationship management (Bustinza et al., 2018). Organization and Culture dimension defines and develops an organizational culture with governance and talent processes to support progress along the digital servitization maturity curve, and the flexibly to achieve growth and innovation objectives. "Digital Service Business Mindset and Culture" describes the diffusion within the companies of a mental model that is oriented towards digital service culture: the company needs to change mental model to view digital service offering as a business logic and perspective on value creation (Uhlmann and Geisert, 2017). Furthermore, "Governance and Leadership" refers to the efficient and effective decision making processes which define the expectations, systems and management of projects related to digital servitization (Vendrell-Herrero et al., 2017). Another significant requirement is the "Organization Design and Talent Management" and cites the transformation of the internal organizational structures by establishing dedicated team/roles/persons for the development of digital service offerings in light of new competitive pressures (Baines et al., 2013). The final requirement is the "Competences", which treats higher and diversified competences that employees need to develop by acquiring new knowledge and ways of working to encounter increasingly interactive tasks, take data-driven decisions, understand customer's problem and interpret its real needs (Paschou et al., 2018).

To define the digital servitization MM phases we used as main reference the MM processes of (Paulk and Curtis, 1993). For simplicity in this study, we use three maturity stages (see Table 3).

Level 1: Beginner is a maturity level where a company has some pilot strategy initiatives and offers base services. The usage level of digital technologies in business processes (production, marketing, HR) is low. Flexibility, integration and collaboration with partners are at low level as well. The customer interaction is distant, while there is a low attitude towards digital servitization. The organization structure and people are not prepared enough for this transformation.

Level 2: Experienced is a maturity level where a company is implementing digital servitization and offers intermediate services. Digital technologies are used in a moderate level in the different business processes The ecosystem is getting digitized while the collaboration is becoming closer. The customer is integrated in the design phase already and the general attitude is encouraged towards the new transformation. The organization structure is suitable for initial projects and people for specific units that have digital servitization projects have the necessary competences.

Level 3: Leader is a maturity level where a company has implemented digital servitization, has a comprehensive vision and offers advanced services. The usage level of digital technologies is high both in the business processes and business models. There is a fully digitized, integrated partner ecosystem built on a flexible and integrity architecture. There is an intimate relationship and personalized communication with the customer while the attitude is comprehensive and promotes digital servitization. The organization structure is well structured and digital competences are prevalent in the whole company.

\section{Concluding remarks}

Although, evidence show that manufacturing companies struggle with comprehending the impact of digital servitization and how to master it, little attention has been devoted so far in developing a tool that 


\begin{tabular}{|c|c|c|}
\hline Dimension & Requirement & Level 1 - Beginner \\
\hline \multirow{4}{*}{ Strategy } & $\begin{array}{c}\text { Strategic } \\
\text { orientation }\end{array}$ & $\begin{array}{l}\text { Limited vision of digital servitization, no documented } \\
\text { implementation target. Strategy initiated and developed. Low } \\
\text { investment. }\end{array}$ \\
\hline & Business model & $\begin{array}{l}\text { Add-on business models use DTs (ICT, IoT) to enable } \\
\text { additional functions or adding personalized services to the } \\
\text { existing physical products or service to facilitate service } \\
\text { provision. }\end{array}$ \\
\hline & $\begin{array}{l}\text { Digital service } \\
\text { offering }\end{array}$ & $\begin{array}{l}\text { Low usage level of DTs is used to provide obligatory product- } \\
\text { related services (base services), such as installation or } \\
\text { maintenance and repair. }\end{array}$ \\
\hline & $\begin{array}{l}\text { Digital service } \\
\text { ecosystem }\end{array}$ & $\begin{array}{l}\text { Company has partnerships with a few stakeholders; low level } \\
\text { collaboration. No flexibility, no additional integration; limited } \\
\text { understanding today, no future shared view. }\end{array}$ \\
\hline \multirow{2}{*}{$\begin{array}{l}\text { Customer } \\
\text { Experience }\end{array}$} & $\begin{array}{l}\text { Customer } \\
\text { centricity }\end{array}$ & $\begin{array}{l}\text { None customer preferences and needs are collected. Interaction } \\
\text { between customer and company is not existent/distant. No } \\
\text { feedbacks from the customer are collected. Impersonal } \\
\text { customer communication. }\end{array}$ \\
\hline & Customer trust & $\begin{array}{l}\text { No documentation; customer does not know when/how the } \\
\text { service provider access the equipment; uncertain about which } \\
\text { activities are performed on the machine. Service technician can } \\
\text { access private/confidential information beyond the service } \\
\text { agreement; no control. }\end{array}$ \\
\hline \multirow{3}{*}{$\begin{array}{l}\text { Business } \\
\text { Processes }\end{array}$} & Production & $\begin{array}{l}\text { Operation process traceability is provided partially; low level } \\
\text { end-to-end visibility and production customization. Standard } \\
\text { agile methods in project execution (e.g. Scrum); no clear } \\
\text { integration and standardization. Integrated supply chain } \\
\text { processes between company, suppliers and customers in terms } \\
\text { of basic data sharing and communication; few software systems } \\
\text { in use and production systems are partially automated. No } \\
\text { activities supporting the digital service innovation, apart from } \\
\text { observations. Data usage in service innovation is at low level. }\end{array}$ \\
\hline & Marketing & $\begin{array}{l}\text { A few analytics studies are conducted and data obtained from } \\
\text { environment is not used in product pricing and dynamic } \\
\text { pricing. The customer has little control over the contribution } \\
\text { process and the provider offers the digital services that chooses. }\end{array}$ \\
\hline & Human resources & $\begin{array}{l}\text { Data is used in a few areas, but company does not share real- } \\
\text { time data with field workers. Traditional recruitment and } \\
\text { training, e-learning is not an option. }\end{array}$ \\
\hline \multirow[t]{2}{*}{$\begin{array}{l}\text { Organization \& } \\
\text { Culture }\end{array}$} & $\begin{array}{l}\text { Digital service } \\
\text { mindset \& culture }\end{array}$ & $\begin{array}{l}\text { Low attitude towards digital servitization. Mistakes and lessons } \\
\text { from failed projects not secretive, digital competences are not } \\
\text { critical, the development of new digital service offerings by } \\
\text { customers is not actively promoted. Low level of knowledge } \\
\text { sharing and no/in limited area collaboration across company. } \\
\text { Home office for employees for whom it makes sense. }\end{array}$ \\
\hline & $\begin{array}{l}\text { Governance and } \\
\text { leadership }\end{array}$ & $\begin{array}{l}\text { De-centralize decision making process. Low } \\
\text { quality/transparency/availability and accuracy of data used for } \\
\text { decision-making processes }\end{array}$ \\
\hline
\end{tabular}

Incremental vision of digital servitization, not fully defined implementation target. Strategy implemented and occasionally multiple areas.

Use Usage-based business models use DTs (loT, cloud computing, ig data) to measure the amount of product usage and allow needs (pay-per-use).

Moderate usage level of DTs (IoT, Cloud computing, Big data, Advanced manufacturing Solutions) is used to provide intermediate services (e.g. remote monitoring)

Company has partnerships with some of stakeholders; medium evel of collaboration. A moderate level of flexibility, integration nd understanding.

No standard approach of preferences/needs collection. The customer is integrated in the early design process in order to lign the product to the customers' needs. Formal feedback is collected after technical assistance interventions.

Some documentation; customer does not know when/how the service provider access the equipment; certain about which activities are performed on the machine. Service technician can access some private/confidential information beyond the service agreement; little control.

Operation process traceability is provided at production line level; medium level end-to-end visibility and production customization; integration and standardization are at a medium level. Integrated supply chain processes between company, and key strategic suppliers/customers in terms of data transfer; some software systems in use and production systems are automated at production line level. Systematic approach for digital service nnovation; company is aware of the process but some activities are still incomplete or inconsistent. Data usage in service Anovation is at medium level.

Analytics studies are conducted and data obtained from environment is used in product pricing and dynamic pricing. The customer has some control over the contribution process and the provider offers the digital services that customer also needs.

Data is used in some areas; company shares real-time data with field workers. Traditional/Digital recruitment, e-learning is an option.

Promote attitude towards digital servitization in a medium level. Evaluate errors, identify the importance of digital competences, the development of new digital service offerings is promoted. Encouragement of knowledge sharing and structured and consistently performed cross-functional collaboration.

Promote central decision making process. Medium quality/transparency/availability and accuracy of data used for decision- making processes. Transformational vision, clearly defined implementation target.
Strategy implemented and regularly reviewed. Enterprise-wide Investment and Innovation management established.

Solution-oriented business models use DTs (IoT, artificial intelligence) to enable the provision of solutions to customers. With the aid of IOT technology, providers are able to offer integrated solutions to customers' needs (subscription availability).

High usage level of DTs (IoT, Big data, Advanced manufacturing solutions, Artificial Intelligence) provides value for both customer and the companies' internal processes creating (advanced services).

a ditized, integrated partner ecosystem; open system buil on a flexible and integrity architecture; clear shared view, today and in the future.

ormal procedures and rules drive customer preferences and needs, used for future strategical decision. Customer and interaction data collected through different channels. Feedbacks are discussed with the client and are explicitly considered in the continuous improvement process by creating common platforms. Intimate relationship.

Documentation; customer knows when/how the service provider access the equipment; certain about which activities are performed on the machine. Service technician cannot acces private/confidential information beyond the service agreement; control.

Operation process traceability is provided at factory level; high level end-to-end visibility and production customization; high level of process standardization. Supply chain systems are fully integrated between company, suppliers and customers which provide real-time planning; lots of software systems in use an production systems are automated in factory level. Quality management and continuous improvement activities are ormalized in the procedure. Data usage in service innovation i at high level.

Analytics studies are conducted and data obtained from environment is used in product pricing and dynamic pricing. The customers are tightly integrated and engaged with the provider's processes and resources. They are jointly able to discover opportunities for value creation.

Data is used in lots of areas; company shares real-time data with field workers. Special training (mixed reality, internal academy) for re-qualification of the employees. Digital recruiting.

Promote digital servitization vision. Evaluate errors to improve processes, digital competences are critical, customers sugges systematically improvements for the digital service offerings. High level of knowledge sharing and sophisticated forms of cross-company collaboration in value creation networks. Great experience on mobile working and little regulations are needed. Re-centralize decision making process. High quality/transparency/availability and accuracy of data for decision- making processes. 


\section{0 \\ IJCIEOM}

International Joint Conference on Industrial Engineering and Operations Management- ABEPRO-ADINGOR-IISE-AIM-ASEM (IJCIEOM 2019). Novi Sad, Serbia, July 15-17th

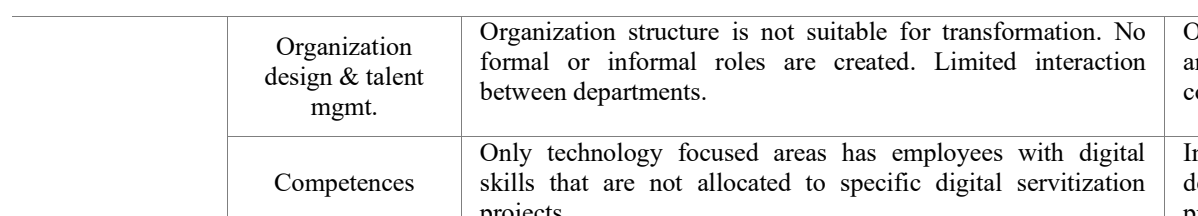

Organization structure is suitable for initial projects. Some roles $\quad$ Well-structured for transformation. Formal roles responsible for are being created. Departments are open to cross-company collaboration. strategic planning, which are well connected within business units. Departments are open to cross-company collaboration to drive improvements.

All across the business, cutting edge digital and analytical skills do specific digital servitization

are prevalent and allocting edge digital and analytical skills projects in same units. 


\section{IJCIEOM}

International Joint Conference on Industrial Engineering and Operations Management- ABEPRO-ADINGOR-IISEAIM-ASEM (IJCIEOM 2019). Novi Sad, Serbia, July 15-17 th

can be used from practitioners. This study presents the development of a new maturity model, that based on specific requirements identified in digital servitization literature and expert interviews, can be used as a management instrument to analyze the current set-up, by assessing the maturity level of strategy, business processes, customer experience, organization and culture. Three levels of maturity have been outlined, and the model constitutes the main contribution of our research, since, to the best of our knowledge, no such kind or model exists for digital servitization in manufacturing.

Coping with the challenges of digital servitization is of considerable interest to both researchers and practitioners. In particular, developing a maturity model for digital servitization 1) contributes to the body of knowledge on enterprise transformation processes, which entail unplanned and radical organizational changes, and 2) represents a practical way of operationalizing the digital servitization process. For practitioners, the results may help managers to assess the status quo of their organization and identify possible new courses of action. This understanding can contribute to more systematic and strategic change processes, as opposed to intuitive reactions to external turbulence. Furthermore, even though a maturity model suggests that a more advanced stage produces better performance, this correlation is not proven and even may not exist at all. The maturity model in this study is simply used for mapping out the typical stages, but every company needs to decide whether the activities in each stage are appropriate, feasible, and relevant for the specific industry, business model, and the competitive context.

Although this paper produced some interesting and useful finding, we would like to point some limitations that need to be considered when interpreting the results. First of all, the development of the model is based exclusively on literature and a number of expert interviews, which makes it conceptual. For that reason, further research could involve more experts, divided into academics and practitioners, aiming at completing the requirement list considering different perspectives. Moreover, we also acknowledge that even though the maturity stages have been carefully developed, based on literature and interviews, a testing and final evaluation of the tool with cases has not yet been conducted.

\section{References}

Adrodegari, F., Saccani, N., Kowalkowski, C., Vilo, J., 2017. PSS business model conceptualization and application*. Prod. Plan. Control 28, 1251-1263. https://doi.org/10.1080/09537287.2017.1363924

Allmendinger, G., Lombreglia, R., 2005. Four strategies for the age of smart services. Harv. Bus. Rev. 83, 131-4, 136, 138 passim.

Alvarez, R.L.P., Martins, M.R., Da Silva, M.T., 2015. Applying the maturity model concept to the servitization process of consumer durables companies in Brazil. J. Manuf. Technol. Manag. 26, 1086-1106. https://doi.org/10.1108/JMTM-04-2014-0050

Ardolino, M., Rapaccini, M., Saccani, N., Gaiardelli, P., Crespi, G., Ruggeri, C., 2018. The role of digital technologies for the service transformation of industrial companies. Int. J. Prod. Res. 56, 2116-2132. https://doi.org/10.1080/00207543.2017.1324224

Baines, T., Lightfoot, H., Smart, P., Fletcher, S., 2013. Servitization of manufacture: Exploring the deployment and skills of people critical to the delivery of advanced services. J. Manuf. Technol. Manag. 24, 637-646. https://doi.org/10.1108/17410381311327431

Baines, T., Lightfoot, H.W., 2014. Servitization of the manufacturing firm: Exploring the operations practices and technologies that deliver advanced services, International Journal of Operations and Production Management. https://doi.org/10.1108/IJOPM02-2012-0086

Becker, J., Knackstedt, R., Janiesch, C., Pfeiffer, D., 2007. Configurative Method Engineering - On the Applicability of Reference Modeling Mechanisms in Method Engineering. Proc. 13th Am. Conf. Inf. Syst. AMCIS 1-12.

Becker, J., Knackstedt, R., Pöppelbuß, J., 2009a. Developing Maturity Models for IT Management. Bus. Inf. Syst. Eng. 1, $213-222$. https://doi.org/10.1007/s12599-009-0044-5

Becker, J., Knackstedt, R., Pöppelbuß, J., 2009b. Developing Maturity Models for IT Management. Bus. Inf. Syst. Eng. 1, $213-222$. https://doi.org/10.1007/s12599-009-0044-5

Belvedere, V., Grando, A., Bielli, P., 2013. A quantitative investigation of the role of Information and Communication Technologies in the implementation of a product-service system. Int. J. Prod. Res. 51, 410-426. https://doi.org/10.1080/00207543.2011.648278

Bonfanti, A., Del Giudice, M., Papa, A., 2018. Italian Craft Firms Between Digital Manufacturing, Open Innovation, and Servitization. J. Knowl. Econ. 9, 136-149. https://doi.org/10.1007/s13132-015-0325-9

Bustinza, O.F., Bigdeli, A.Z., Baines, T., Elliot, C., 2015. Servitization and Competitive Advantage: The Importance of Organizational Structure and Value Chain Position. Res. Manag. 58, 53-60. https://doi.org/10.5437/08956308x5805354 


\section{ICIEOM}

International Joint Conference on Industrial Engineering and Operations Management- ABEPRO-ADINGOR-IISEAIM-ASEM (IJCIEOM 2019). Novi Sad, Serbia, July 15-17 th

Bustinza, O.F., Gomes, E., Vendrell, F., Shlomo, H., 2018. An organizational change framework for digital servitization : Evidence from the Veneto region * 27, 111-119. https://doi.org/10.1002/jsc.2186

Cenamor, J., Rönnberg, D., Parida, V., 2017. Adopting a platform approach in servitization: Leveraging the value of digitalization. Int. J. Prod. Econ. 192, 54-65. https://doi.org/10.1016/j.ijpe.2016.12.033

Coreynen, W., Matthyssens, P., Van Bockhaven, W., 2017. Boosting servitization through digitization: Pathways and dynamic resource configurations for manufacturers. Ind. Mark. Manag. 60, 42-53. https://doi.org/10.1016/j.indmarman.2016.04.012

Frank, A.G., Mendes, G.H.S., Ayala, N.F., Ghezzi, A., 2019. Servitization and Industry 4.0 convergence in the digital transformation of product firms: A business model innovation perspective. Technol. Forecast. Soc. Change 141, $341-351$. https://doi.org/10.1016/j.techfore.2019.01.014

Grubic, T., 2018. Remote monitoring technology and servitization: Exploring the relationship. Comput. Ind. 100, $148-158$. https://doi.org/10.1016/j.compind.2018.05.002

Holler, J., Tsiatsis, V., Mulligan, C., 2017. Toward a Machine Intelligence Layer for Diverse Industrial IoT Use Cases. IEEE Intell. Syst. 32, 64-71. https://doi.org/10.1109/MIS.2017.3121543

Kohtamäki, M., Parida, V., Oghazi, P., Gebauer, H., Baines, T., 2019. Digital servitization business models in ecosystems : A theory of the firm. J. Bus. Res.

Lerch, C., Gotsch, M., 2015. Digitalized Product-Service Systems in Manufacturing Firms: A Case Study Analysis. Res. Manag. 58, 45-52. https://doi.org/10.5437/08956308x5805357

Neff, A.A., Hamel, F., Herz, T.P., Uebernickel, F., Brenner, W., Vom Brocke, J., 2014. Developing a maturity model for service systems in heavy equipment manufacturing enterprises. Inf. Manag. 51, 895-911. https://doi.org/10.1016/j.im.2014.05.001

Ostrom, A.L., Patrício, L., Voss, C., Voss, C.A., Patrı, L., 2015. Service Research Priorities in a Rapidly Changing Context Service Research Priorities in a Rapidly Changing Context. https://doi.org/10.1177/1094670515576315

Paluch, S., Wunderlich, N. V., 2016. Contrasting risk perceptions of technology-based service innovations in inter-organizational settings. J. Bus. Res. 69, 2424-2431. https://doi.org/10.1016/j.jbusres.2016.01.012

Paschou, Theoni, Adrodegari, F., Perona, M., Saccani, N., 2018. Digital servitization in manufacturing as a new stream of research: a review and a further research, in: A Research Agenda for Service Innovation. Cheltenham, UK: Edward Elgar Publishing, pp. 148-165. https://doi.org/https://doi.org/10.4337/9781786433459.00012

Paschou, T, Rapaccini, M., Adrodegari, F., Saccani, N., 2018. Competences in digital servitization: A new framework. 23rd Summer Sch. "Francesco Turco" - Ind. Syst. Eng. 2018 A4 - Animp; Bosch; Cineca; Fincantieri; Inven. Wide 2018-Septe, 381-387.

Paulk, C., Curtis, B., 1993. Capability Maturity Model, Version 1+1 18-27. https://doi.org/10.1109/52.219617

Porter, M.E., Heppelmann, J.E., 2014. How \{Smart\}, \{Connected\}\{Products\} \{Are\} \{Transforming\} \{Competition\}. Harv. Bus. Rev.

Rymaszewska, A., Helo, P., Gunasekaran, A., 2017. IoT powered servitization of manufacturing-an exploratory case study. Int. J. Prod. Econ. 192, 92-105. https://doi.org/https://doi.org/10.1016/j.ijpe.2017.02.016

Sklyar, A., Kowalkowski, C., Tronvoll, B., Sörhammar, D., 2019a. Organizing for digital servitization: A service ecosystem perspective. J. Bus. Res. 0-1. https://doi.org/10.1016/j.jbusres.2019.02.012

Sklyar, A., Kowalkowski, C., Tronvoll, B., Sörhammar, D., 2019b. Organizing for digital servitization: A service ecosystem perspective. J. Bus. Res. 0-1. https://doi.org/10.1016/j.jbusres.2019.02.012

Uhlmann, E., Geisert, C., 2017. INTELLIGENT PRODUCTION SYSTEMS IN THE ERA OF INDUSTRIE 4 . 0 - CHANGING MINDSETS AND BUSINESS MODELS Numerous definitions of machine intelligence exist in literature . Legg and Hutter propose in [ 1 ] the following informal definition of machine intellige 17.

Valencia, A., Mugge, R., Schoormans, J.P.L., Schifferstein, R., 2015. The Design of Smart Product-Service Systems (PSSs): An Exploration of Design Characteristics How background colors affect food perception View project Sensory and Instrumental Analysis of Food Aromas (PhD project) View project. Int. J. Des. 9.

Vendrell-Herrero, F., Bustinza, O.F., Parry, G., Georgantzis, N., 2017. Servitization, digitization and supply chain interdependency. Ind. Mark. Manag. 60, 69-81. https://doi.org/10.1016/j.indmarman.2016.06.013

Wendler, R., 2012. The maturity of maturity model research: A systematic mapping study. Inf. Softw. Technol. 54, 1317-1339. https://doi.org/10.1016/j.infsof.2012.07.007 